\title{
Potencialidades e limites da relação entre turismo e educação: um estudo no Ensino Fundamental II em escolas públicas municipais de Recife e Olinda (Pernambuco, Brasil)
}

\section{Potentiality and limitations of the relationship between tourism and education: a study in Elementary Education at public schools of Recife and Olinda (Pernambuco, Brazil)}

\author{
Mariana Albert da Silva (SILVA, M. A. da) \\ Luciana Araújo de Holanda (HOLANDA, L. A. de) ${ }^{* *}$ \\ Maria Helena Cavalcanti da Silva (SILVA, M. H. C. da) ${ }^{* * *}$ \\ Sérgio Rodrigues Leal (LEAL, S. R.)
}

\begin{abstract}
RESUMO - Reconhecendo o grande potencial educativo do turismo, tendo em vista seu caráter sociocultural, econômico, ambiental e político, investigou-se como o turismo tem sido trabalhado no Ensino Fundamental II das escolas públicas municipais de Recife e Olinda, principais destinos turísticos do Estado de Pernambuco, Brasil. Foram feitas pesquisas bibliográfica, documental e de campo, que consistiu na aplicação de questionários e na realização de entrevistas com gestores de tais escolas. Constatou-se que nenhuma das escolas pesquisadas incluía o turismo como tema transversal ou como disciplina nos currículos escolares e apenas algumas delas adotavam a prática do turismo pedagógico. Embora o envolvimento dos professores e dos alunos tenha sido satisfatório, a escassez de material didático que relacione turismo e educação, a falta de exemplos práticos para embasar os educadores e as restrições orçamentárias foram apontados como fatores limitantes para a inserção do turismo nestas escolas.
\end{abstract}

Palavras-chave: Turismo; Ensino fundamental; Escola pública; Recife; Olinda.

\footnotetext{
* Graduação em Turismo pela Universidade Federal de Pernambuco (UFPE). Estudante de Licenciatura em Línguas, Literatura e Civilizações Estrangeiras pela Universidade de Estrasburgo (França). Endereço para correspondência: 22 Route du Polygone. 67100 - Strasbourg - France. Telefone/Fax: 0033762689875. E-mail: mariana.albert@gmail.com.

** Graduação em Turismo pela Universidade Católica de Pernambuco (UNICAP). Especialização em Planejamento e Gestão Organizacional pela Universidade de Pernambuco (UPE) e em Relações Públicas para o Turismo pela Escola Superior de Relações Públicas (ESURP). Mestrado e Doutorado em Administração pela Universidade Federal de Pernambuco (UFPE). Professora do Departamento de Hotelaria e Turismo da Universidade Federal de Pernambuco (DHT/UFPE). Endereço profissional: DHT/UFPE. Rua Profa. Teresa Melias, s./n. - Campus Recife. Cidade Universitária. CEP: 50670-901 Recife - Pernambuco (Brasil). Telefone/Fax: (81) 2126-8751. E-mail: luciana.holanda@ufpe.br.

*** Graduação em Turismo pela Universidade Federal de Pernambuco (UFPE). Especialização em Administração de Marketing pela Universidade de Pernambuco (UPE) e em Educação a Distância pela Faculdade Integrada de Jacarepaguá (FIJ). Mestrado em Gestão do Desenvolvimento Local Sustentável pela UPE. Professora do Departamento de Hotelaria e Turismo da UFPE. E-mail: maria.hcsilva2@ufpe.br

**** Graduação em Turismo pela Universidade Federal de Pernambuco (UFPE). MBA em Administração de Marketing de Serviços pela UFPE. Mestre em Turismo pela Universidade James Cook (Austrália). Ph. D. pela Universidade de Surrey (Reino Unido). Professor do Departamento de Hotelaria e Turismo da UFPE. E-mail: sergio.rleal@ufpe.br.
} 
ABSTRACT - Recognizing the great educational potential of tourism, given its sociocultural, economic, environmental and political aspects, an investigation on how tourism has been dealt with in elementary education at public schools of Recife and Olinda, the major tourist destinations of Pernambuco State, Brazil, was conducted. In order to do so, bibliographic, documentary and field research were done. The field research was performed by questionnaires and interviews with managers of such schools. It was found that none of the schools surveyed include tourism as a crosscutting theme or as a subject in school curricula and only some of them adopted the practice of pedagogical tourism. Although the involvement of teachers and students has been satisfactory, the lack of teaching material which connects tourism and education, the shortage of practical examples to support educators and budget constraints were mentioned as limiting factors to the inclusion of tourism in these schools.

Key words: Tourism; Elementary Education; Public School; Recife; Olinda. 


\section{INTRODUÇÃO}

O reconhecimento do potencial educativo do turismo remonta ao século XVIII, quando as viagens eram consideradas fontes de aprendizado para os jovens da aristocracia inglesa que eram conduzidos a outros países europeus, principalmente França e Itália, nos denominados Petit e Grand Tour, a depender da abrangência dos locais visitados. Viajar consistia um complemento indispensável à formação por proporcionar observação direta dos usos e costumes, política, religião e arte de outras nações e com isto propiciar resultados pedagógicos superiores aos produzidos pelas escolas da época (BARRETTO, 2003, p. 49). Estas "viagens de estudo" assumiam o valor de um diploma que conferia a seus detentores significativo status social (ANDRADE, 2006, p. 9).

No contexto atual, o turismo continua a apresentar grande potencial educativo tendo em vista seu caráter sociocultural, econômico, ambiental e político, suscitando discussões na academia há mais de trinta anos. Alguns autores utilizam a expressão "educação turística" para abordar as inter-relações entre educação e turismo, porém, empregam-na com diversas conotações, englobando variados níveis de ensino da educação formal, bem como a educação informal.

Para Fúster (1991 apud FONSECA FILHO, 2007, p. 32) ${ }^{1}$, um dos pioneiros a tratar do tema, o ensino do turismo pode ter início nas primeiras séries escolares, por meio de cartilhas e aulas que versem sobre a temática (educação formal), bem como pode ser conduzido através de campanhas publicitárias divulgadas em distintos meios de comunicação como televisão, rádio, impressos, por exemplo, visando à sensibilização e, por conseguinte, ao desenvolvimento de uma consciência turística e cidadã (educação não formal).

Diante da polissemia da expressão "educação turística" e da abrangência da interface entre educação e turismo, sugere-se, neste trabalho, abordar as relações entre ambas áreas por meio de duas grandes perspectivas que, embora distintas, são complementares: a educação para o turismo e a educação pelo turismo.

A educação para o turismo envolve a sensibilização e conscientização dos atores turísticos, sobretudo turistas e autóctones, visando à minimização dos impactos

\footnotetext{
${ }^{1}$ FÚSTER, L. F. Introducción a la Teoría y Técnica del Turismo. Madrid: Alianza Universidad Textos, 1991.
} 
negativos e maximização dos impactos positivos gerados pela atividade turística no núcleo receptor (cursos de extensão universitária e de educação não-formal ofertados por instituições que não pertençam a redes escolares de ensino, tais como secretarias de turismo, organizações não-governamentais, etc.), bem como a formação e qualificação de mão de obra para o setor turístico (cursos técnico/profissionalizante, superior e livre), assunto tratado por diversos autores nacionais tais como Rebelo (1998), Ruschmann (1999), Silva (2002) e Fonseca Filho (2007).

A educação pelo turismo engloba a utilização do turismo como ferramenta pedagógica para auxiliar a formação de estudantes na educação básica (ensino infantil, fundamental e médio) possibilitando a vivência, contextualização e assimilação de conteúdos previstos nos perfis curriculares de modo a auxiliar o processo de ensinoaprendizagem. Assim sendo, o turismo pode ser inserido nas escolas seja como conteúdo transversal, disciplina constante na grade curricular de determinada série e através do turismo pedagógico associado à realização de visitas e excursões didáticas, podendo esta última forma ser utilizada como atividade extracurricular nas duas primeiras. Esta vertente tem sido abordada, em âmbito nacional, por Portuguez (2001), Ribas (2002), Peccatiello (2005), Fonseca Filho (2007; 2010), dentre outros. Vale salientar que a maior parte da produção científica está direcionada ao ensino superior ou profissionalizante, havendo poucos estudos no âmbito do ensino fundamental e médio (FONSECA FILHO, 2007, p. 30).

Neste panorama traçado, o presente trabalho se propõe a contribuir com a perspectiva da educação pelo turismo ao descrever como o turismo tem sido trabalhado no Ensino Fundamental II das escolas públicas municipais de Recife e Olinda, em Pernambuco (Brasil).

A escolha por este lócus de pesquisa deve-se à projeção de ambas cidades dentro do cenário turístico estadual e nacional. Sob o rótulo "Recife/Olinda", os municípios foram eleitos como um dos 65 destinos indutores do turismo no Brasil (MTUR, 2010), demonstrando desta maneira sua relevância turística. Destaca-se, ainda, o fato do sítio histórico de Olinda ser tombado pela Organização das Nações Unidas para a Educação, a Ciência e a Cultura (UNESCO) como Patrimônio da Humanidade desde 1982. (UNESCO, 2013), o que a torna uma das cidades de maior atratividade turística em Pernambuco. 
A opção pelo recorte no Ensino Fundamental II segue a mesma lógica adotada pelo governo federal que, em dois dos três programas que elaborou, direcionou suas ações a este nível educacional ${ }^{2}$. Entende-se que, no Ensino Fundamental I, como os alunos ainda são crianças entre 6 e 10 anos, podem não ter ainda habilidades e maturidade para abordar algumas questões relacionadas ao turismo. Já no ensino médio, apesar de já possuírem idade entre 15 e 18 anos, considerados mais maduros, o foco do ensino do turismo geralmente tende a ser apenas na profissionalização. Assim sendo, acredita-se que a inserção do turismo como prática pedagógica parece ser mais adequada ao Ensino Fundamental II pelo fato de englobar a faixa etária entre 11 e 14 anos, ou seja, período da adolescência marcado por novas possibilidades de compreensão do mundo em função do desenvolvimento do pensamento lógico-formal, da capacidade de formular hipóteses sofisticadas e de acompanhar e elaborar raciocínios complexos (MEC, 1997, p. 113).

Partindo da problemática exposta, apresenta-se nas sessões a seguir o referencial teórico utilizado para fundamentar a presente pesquisa, os procedimentos metodológicos empregados em sua operacionalização, os resultados desta investigação, além das referências consultadas.

\section{A EDUCAÇÃO PELO TURISMO}

A inclusão do turismo nas escolas de municípios turísticos contribui para contextualizar os conteúdos das disciplinas tradicionais com a realidade local, colaborando, por conseguinte, para a melhoria do rendimento escolar, além de auxiliar a formação de cidadãos críticos em relação à degradação dos patrimônios ambientais e histórico-culturais, aculturação, exploração sexual, dentre outros impactos negativos atribuídos ao fenômeno turístico, potencializando assim, os impactos positivos da

\footnotetext{
${ }^{2}$ Dos programas de inserção do turismo nas escolas, elaborados pelo governo federal, o "Programa de Iniciação Escolar para o Turismo" foi direcionado para a $6^{\mathrm{a}}$ a $8^{\mathrm{a}}$ série; o "Embarque Nessa" para a $6^{\mathrm{a}}$ série (FONSECA FILHO, 2007; 2010; FONSECA FILHO; ALDRIGUI, 2009); e a "Série Caminhos do Futuro" para o ensino fundamental e médio consistindo em um conjunto de manuais intitulados: Aprendiz de Lazer e Turismo; Comunicação e Turismo; Cultura e Turismo; Ética, Meio Ambiente e Cidadania para o Turismo; Finanças, Administração e Tecnologia para o Turismo; Geografia e Cartografia para o Turismo; Hotelaria e Hospitalidade; e Passaporte para o Mundo (MTUR, 2007).
} 
atividade turística que, quando bem planejada, pode contribuir, significativamente, para o desenvolvimento local sustentável (REBELO, 1998).

A educação pelo turismo possibilita trazer para a sala de aula assuntos presentes na realidade vivida pelos estudantes que residem num município com potencialidade turística (FONSECA FILHO, 2007, p. 38), bem como, sair da sala de aula e ter acesso a patrimônios históricos, culturais e ambientais, além do contato com turistas de outras culturas e idiomas, enriquecendo o processo de ensino-aprendizagem.

O envolvimento dos alunos com o contexto no qual estão inseridos permite-lhes conhecer seu espaço e os valores de sua comunidade (RIBAS, 2002, p. 18). Ao conduzir o adolescente a pensar na realidade que o cerca e nas mudanças que ocorrem ao seu redor, busca-se formar cidadãos críticos e participativos (FONSECA FILHO, 2007, p. 28), sujeitos atuantes capazes de "modificar, desenvolver e enriquecer os instrumentos de ação e interpretação no âmbito social" (PECCATTIELO, 2005, p. 10).

Faz-se mister enfatizar que não se almeja simplesmente preparar o educando para servir ou atender bem o turista. O objetivo da educação pelo turismo é muito mais amplo, aspira-se sensibilizar o aluno como sujeito atuante, agente da realidade, "capaz de modificar, desenvolver e enriquecer os instrumentos de ação e interpretação no âmbito social" (PECCATTIELO, 2005, p. 10).

Assim sendo, a educação pelo turismo estará conduzindo o jovem a pensar nas mudanças que ocorrem ao seu redor, oferecendo-lhe ferramentas para que consiga produzir conhecimento, ou seja, "fazer-saber", em detrimento de "saber-fazer" (MOESCH, 2002) que normalmente é enfatizado quando há a inclusão do turismo conjugado com a educação formal.

A educação pelo turismo pode ocorrer de, pelo menos, três maneiras: seja como tema transversal, disciplina e através da prática do turismo pedagógico, podendo esta última forma ser utilizada como atividade extracurricular nas duas primeiras. Qualquer uma destas modalidades pode ajudar na inclusão de temáticas locais dentro dos conteúdos tradicionais, ajustando o saber local ao conhecimento específico que se pretende obter com o ensino das disciplinas obrigatórias (FONSECA FILHO, 2007, p. 38). Ver-se-á adiante as especificidades de cada uma destas práticas pedagógicas. 


\subsection{TURISMO COMO TEMA TRANSVERSAL}

Temas transversais são oriundos de debates e questionamentos de grupos politicamente organizados, presentes em diversos países, que discutem o papel destinado à escola, em uma sociedade diversificada e globalizada, e quais conteúdos devem ser abordados no espaço escolar (ARAÚJO, 1998).

No Brasil, a Lei de Diretrizes e Bases (LDB) n 9.394 de 20/12/96 (atualizada em 25/10/2011) (BRASIL, 1996), e os Parâmetros Curriculares Nacionais (PCNs), elaborados pelo Ministério da Educação (MEC, 1997), forneceram o amparo legal e proporcionam inúmeras oportunidades de se extrair benefícios da inter-relação entre turismo e educação. Fundamentada nos princípios constitucionais, a legislação prevê que os currículos do ensino fundamental e médio tenham uma base nacional comum, a ser complementada, em cada sistema de ensino e estabelecimento escolar, por uma parte diversificada de acordo com características regionais e locais da sociedade, incorporando temas transversais como ética, cidadania, pluralidade cultural, meio ambiente, dentre outros.

Os temas transversais não devem ser tratados como novas disciplinas, mas, precisam ser abordados a partir das perspectivas da inter e da transdisciplinaridade que se alimentam mutuamente na prática pedagógica (MEC, 1997, p. 40). Os conteúdos curriculares tradicionais compõem o eixo longitudinal do sistema educacional e, em volta desses campos do conhecimento, devem transcorrer, transversalmente, as questões atreladas ao cotidiano da sociedade (ARAÚJO 1998, p. 13).

Em face de sua complexidade e por caracterizar-se como sendo uma área de estudo multi, inter e transdisciplinar (REJOWSKI, 1998; ANSARAH, 2002; MOESCH, 2002), o turismo pode servir como objeto que viabilize a interação destes temas apontados pelos PCNs (MEC, 1997) para serem trabalhados no ensino básico das escolas brasileiras, com as áreas tradicionais, pois todas estas dimensões estão contidas nele. Apresenta-se, neste estudo, possibilidades detectadas por seus autores de vincular cada um dos temas transversais sugeridos pelo MEC (1997) à atividade turística. Em se tratando do tema ética, pode-se trabalhá-lo em sala de aula a partir de situações próprias da atividade turística como, por exemplo, analisando as atitudes da comunidade receptora em relação aos visitantes e destes em relação à comunidade, discutindo com 
os estudantes a necessidade do respeito mútuo entre os grupos e evitando, desta forma, a propagação de ações como a de exploração. Desta forma, aborda-se conjuntamente os quatro eixos estabelecidos pelos PCNs (MEC, 1997) que possuem relação com o tema transversal ética, a saber: o respeito mútuo, a justiça, o diálogo e a solidariedade.

Já a questão da pluralidade cultural deve enfatizar as diversidades étnicas, a contribuição dos diferentes povos e culturas na sociedade brasileira, valorizando a herança que cada elemento deixou para a formação da sociedade atual; as diferenças religiosas, regionais e até mesmo entre países e continentes; visando com isto eliminar todo tipo de preconceito, racismo e etnocentrismo. A abordagem deste tema, com vistas ao turismo, também pode contribuir para valorizar e viabilizar a manutenção da identidade cultural local, buscando demonstrar a importância do patrimônio histórico e cultural (tanto material, quanto imaterial) de uma localidade, que, por ser tão valioso, desperta o interesse de pessoas de outros lugares e os motiva a visitar aquele determinado espaço. Portanto, por ter sido construído e pertencer a todos, dever ser cuidado, admirado, respeitado e preservado.

Ao abordar os conceitos regionais e locais, enfatizando as origens, progressos e a contemporaneidade, os estudantes compreendem a cultura como dinâmica e que as alterações sociais ocorridas durante os anos podem transformar - e transformam - a atualidade, sendo estas variações, via de regra, a descaracterização do local. Entendem que conservando a memória viva, preservando os patrimônios culturais, os alunos embarcam num processo de reflexão a respeito da realidade de uma localidade, sobre os impactos do turismo que acontecem em um município e de como devem se portar para tornarem mínimos os aspectos negativos e expandir os positivos da atividade turística (FONSECA FILHO, 2007). Este assunto pode ser trabalhado nas aulas de História, Artes, Língua Portuguesa, Geografia, Literatura e até mesmo na Biologia ao serem estudados os fenótipos humanos.

A preocupação com o meio ambiente, por ser um tema com tanta exposição midiática desde a realização da ECO $92^{3}$, também pode ser abordada através do turismo, enfatizando a educação ambiental, a importância da conservação e preservação dos espaços naturais e a relevância destes para a localidade, mas, também, deve-se chamar atenção para os cuidados que se deve ter com o seu próprio ambiente (cidade, bairro,

\footnotetext{
${ }^{3}$ Conferência das Nações Unidas sobre o Meio Ambiente e o Desenvolvimento (CNUMAD), conhecida também como ECO-92 e Rio-92.
} 
rua, escola), ou seja, rompendo a ideia de que o meio ambiente corresponde apenas à natureza, quando na verdade trata de todo o entorno de onde se vive. Deve ser despertada uma postura de cuidado e respeito com o lugar onde se reside e também com os lugares que se visita, pois estes espaços são importantes não só para o desenvolvimento do Turismo, como, também, para o bem-estar das comunidades locais.

A temática sexualidade pode ser trabalhada junto aos educandos utilizando, por exemplo, o Estatuto da Criança e do Adolescente (Lei n॰ 8069 de 13 de julho de 1990) (BRASIL, 2010), de forma que os alunos possam compreender que a exploração sexual infantil é proibida, estando os jovens com idade de até 18 anos apoiados e acobertados pela lei. Além disso, abordar as questões relacionadas à prática ilegal da exploração sexual por parte dos turistas pode ser mais uma maneira de trabalhar o tema transversal em tela. Esta discussão despertará nos estudantes a consciência dos seus direitos e os incentivará para que tomem atitudes defensivas caso sejam aliciados, além de contribuir para a erradicação desta prática criminosa. É possível que haja, também, uma relação com o tema transversal da saúde ao serem abordados temas como gravidez na adolescência e doenças sexualmente transmissíveis.

O último tema transversal sugerido pelos PCNs (MEC, 1997, p. 35) são os denominados Temas Locais, cuja função é: "contemplar os temas de interesse específíco de uma determinada realidade a serem definidos no âmbito do Estado, da cidade e/ou escola". O MEC (Ibidem) recomenda que "uma vez reconhecida a urgência social de um problema local, este poderá receber o mesmo tratamento dado aos outros Temas Transversais". Sendo assim, dentro dos temas locais, as escolas que se localizam em municípios turísticos podem utilizar-se do fenômeno para abordar as mais diversas questões relacionadas ao mesmo.

Estes exemplos ilustrativos, esboçados a partir das reflexões dos autores tomando por base os PCNs (MEC, 1997), revelam o potencial que o turismo detém para ser utilizado como elemento de contextualização dos temas transversais e temas locais em disciplinas tais como história, artes, literatura (pluralidade cultural), geografia (meio ambiente), ciências, biologia, química (saúde), filosofia (ética), etc. Pelo exposto, conclui-se que o turismo pode, facilmente, ser desenvolvido como um tema transversal utilizando-se as características históricas, geográficas, culturais e turísticas locais que 
são, diretamente, relacionadas à realidade vivida pelos educandos e educadores, com o intuito de transformá-las em conhecimento (FONSECA FILHO, 2007, p. 110).

\subsection{TURISMO COMO DISCIPLINA}

A inserção de uma disciplina específica de turismo no currículo escolar do ensino básico permite a diversificação do currículo com temas locais e transversais, como preconiza a LDB. Esta prática vem ganhando espaço no Brasil, porém não tem sido muito discutida entre os pesquisadores e tem gerado controvérsias.

O estudo mais relevante e detalhado encontrado sobre o assunto é a dissertação de mestrado de Ari da Silva Fonseca Filho (2007), onde o autor fez um estudo de caso em uma escola de ensino fundamental e médio no município Águas de São Pedro-SP. Em um artigo, Elzário Pereira da Silva Júnior (2004) discutiu a experiência da inclusão da disciplina "Estudos Turísticos e Meio Ambiente" nos municípios turísticos do Rio de Janeiro. Já no livro "Consumo e Espaço: turismo, lazer e outros temas", Anderson Pereira Portuguez (2001) trata deste assunto, porém de maneira tangenciada. Estes três autores serviram de base para a construção desta parte do referencial.

A inclusão de uma disciplina de turismo no ensino fundamental e médio tem ocorrido para atender, principalmente, a duas finalidades: ensinar sobre cultura, patrimônios naturais e culturais, meio ambiente, por meio do turismo; preparar os alunos para uma boa recepção e atendimento dos turistas, tendo em vista a profissionalização para o turismo (FONSECA FILHO, 2007, p. 16).

Na perspectiva da educação pelo turismo, Silva Júnior (2004, p. 28) defende a conversão do turismo em disciplina específica, mesmo que optativa, cuja ementa deve considerar as especificidades locais, a realidade dos municípios e os temas transversais. Tal disciplina consubstancia-se em uma forma de atualizar o ensino e proporcionar oportunidade de debater novos temas emergentes, em face da complexidade sócioeconômica-ambiental do fenômeno turístico.

Por outro lado, Portuguez (2001, p. 121) considera que a disciplinarização do turismo é complexa e questionável por causa de implicações como a fragmentação do conhecimento, a demanda por docentes atualizados em relação aos conhecimentos específicos de turismo, a ruptura com a espontaneidade de internalização da realidade 
(pois requer a preocupação com notas e presença para aprovação), comprometendo, assim, o processo de conscientização, criatividade e criticidade em relação ao estudo do turismo e à realidade turística vivenciada. Fonseca Filho (2007) corrobora com essa visão e não considera a disciplinarização a maneira ideal de inserir a temática do turismo nas escolas de ensino básico.

Mesmo favorável à instituição da disciplina de Turismo no ensino básico, Silva Júnior (2004, p. 24) reconhece a existência de entraves para sua concretização, sendo o principal deles, na sua ótica, a limitação dos professores de outras disciplinas em delinear um plano de aula pertinente, sem assistência de um turismólogo, por isto recomenda a formação de uma equipe multidisciplinar. Isto minimiza o direcionamento do ensino do turismo para a área de formação de cada professor, como apontado por Portuguez (2001, p. 127).

Outro fator que inibe a implantação da disciplina de Turismo nas séries de ensino básico é o material didático. Segundo Portuguez (2001, p. 118), os livros didáticos, no Brasil, têm dado ao tema uma abordagem apática. Apesar de toda a relevância da atividade, a mesma continua sendo ignorada, e, quando é citada, trata-se de acanhadas observações. Ao analisar alguns livros didáticos, Fonseca Filho (2007, p. 93) concluiu que o número de livros de Geografia que abordam o tema do turismo é crescente, no entanto, na maioria deles, o assunto é tratado apenas a partir da perspectiva econômica e exposição das belezas naturais brasileiras, tendo uma visão limitada do fenômeno. Portanto, verifica-se que a escassez e deficiência de material didático é um entrave que dificulta o embasamento dos professores que pretendem elaborar a disciplina de Turismo.

Para que, efetivamente, seja válida a introdução da disciplina de Turismo nas escolas de ensino fundamental, é preciso que um grupo de docentes multidisciplinar faça um mapeamento dos temas relevantes a cada série, para que sejam delimitados e estabelecidos os conteúdos que necessitam ser abordados, de modo que seja levada em consideração a realidade dos alunos, e, ainda, para que os conteúdos sejam construídos com a finalidade de preencher as lacunas na formação dos mesmos.

Acredita-se que a disciplina de turismo, se bem planejada, de modo a considerar as demandas dos alunos, da comunidade e da escola, bem como havendo um diálogo entre as áreas afins pode ajudar na internalização de conteúdos das disciplinas 
tradicionais, assim como ampliar o entendimento dos educandos acerca do fenômeno turístico e despertar para atitudes responsáveis, enquanto turistas, perante as localidades visitadas e a comunidade receptora.

\subsection{TURISMO PEDAGÓGICO}

Também denominado de "turismo científico" (ANDRADE, 2006, p. 72) e de “turismo educacional" (BENI, 2001, p. 426), o turismo pedagógico remonta às viagens realizadas pelos filhos das elites européias acompanhados de tutores, como abordado na introdução. Hoje, é praticado através de visitas técnicas, excursões didáticas, aulaspasseio, dentre outras nomenclaturas empregadas para este tipo de atividade extraclasse.

$\mathrm{O}$ turismo pedagógico engloba qualquer tipo de deslocamento do ambiente escolar, podendo ser visitas a museus, parques, participação em acampamento, desde que estas atividades proporcionem situações de aprendizagem ligadas aos conteúdos do currículo e despertem os alunos para a realidade (VINHA et al., 2005, p. 6).

Em essência, trata-se de uma maneira "de tirar o aluno do restrito espaço de uma sala de aula, para um contexto mais amplo: o da realidade turística de seu município" (SILVEIRA; MARTINS; VIEIRA, 2008, p. 4) proporcionando a convivência entre pessoas de culturas diferentes e oportunizando a prática do "aprender a conhecer, a fazer, a conviver e a ser" (BONFIM, 2010, p. 126). Esta pedagogia participativa é estimulante porque desenvolve os aspectos cognitivos, afetivos e sociais dos alunos através do lúdico e do entretenimento, proporcionando aprendizagem prazerosa, fruto da ampliação do conhecimento, do esclarecimento, da convivência (VINHA et al., 2005, p. $15)$.

Embora proporcione um processo de aprendizagem de maneira lúdica, envolvendo momentos de lazer, não deve ser realizado com este fim per si (ANDRIOLO; FAUSTINO, 1997, p. 165). Tem que estar ligado ao currículo escolar e ser orientado para alcançar os objetivos do projeto pedagógico da escola. O que se pretende com esta prática não é um passeio comum, mas uma atividade educativa que aproximará a teoria da realidade, em um ambiente de ensino fora dos muros das salas de aula (SILVEIRA; MARTINS; VIEIRA, 2008, p. 4). 
A dinâmica espacial está em constante transformação, seja por causas naturais ou pela ação do homem, o que torna difícil a compreensão, por parte dos estudantes, e a transmissão, por parte dos professores, de alguns conteúdos disciplinares e de valores sociais, culturais e ecológicos sem sua contextualização e vivência (PECCATTIELO, 2005, p. 6). O turismo pode contribuir neste sentido, pois a interação com os professores, os companheiros de sala, os recursos didáticos e contato com o meio social proporciona ao aluno a construção de significados sobre os conteúdos da aprendizagem (PECCATTIELO, 2005, p. 10).

Por sua interatividade e ludicidade, a prática do turismo pedagógico desperta nos alunos curiosidade e maior interesse no objeto de estudo, facilitando o processo ensinoaprendizagem, ademais de contextualizar os temas vistos em classe e levar os estudantes a vivenciarem a realidade da localidade e refletir sobre a mesma (NADER; POZI; CONGRO, 2004).

Esta prática pedagógica deve ser muito bem planejada por equipes multidisciplinares, formadas por turismólogos e professores das diversas áreas (VINHA et al., 2005, p. 6). Devem-se realizar estudos prévios do local onde se deseja visitar, relacionando os mesmos com os conteúdos vistos nas salas de aula (RAYKIL; RAYKIL, 2005, p. 2), tendo em vista o potencial do turismo pedagógico de abordar, concomitantemente, conteúdos das diversas disciplinas tradicionais (PECCATIELLO, 2005, p. 6).

A realização de uma excursão com fins na educação requer três etapas nas quais os sujeitos aprimoram as habilidades de organização, pró-atividade e participação; observam e realizam a coleta de dados; e, por fim, há a sistematização do que foi aprendido. Tais etapas, de acordo com Vinha et al. (2005, p. 7) e Bonfim (2010, p.124), envolvem:

- O planejamento, ou seja, a organização da atividade que deve incluir a participação dos alunos em todas as fases desde a escolha do lugar da visitação, elaboração das regras e pesquisa prévia sobre o destino a ser visitado.

- A própria visita, onde há a observação da localidade, coleta de dados e o direcionamento do olhar para a paisagem.

- O retorno, quando há a sistematização do aprendizado através dos relatórios, produção de textos, painéis com fotos e desenhos. 
Pelo exposto, percebe-se que a prática do turismo pedagógico pode ser incorporada tanto na abordagem do turismo como tema transversal quanto do turismo como disciplina, pois se utiliza da própria atividade turística como subsídio para despertar o interesse dos educandos nos conteúdos vistos na sala de aula.

Buscou-se demonstrar, nesta seção, alguns dos muitos benefícios que podem ser extraídos da inter-relação entre o turismo e a educação. Com o objetivo de verificar como o turismo tem sido trabalhado nas escolas públicas de Ensino Fundamental II em Recife e Olinda, foram realizados os procedimentos metodológicos descritos na próxima seção.

\section{PROCEDIMENTOS METODOLÓGICOS}

Tal como a maior parte das pesquisas sobre educação, o presente estudo possui natureza descritiva (TRIVIÑOS, 1987) que tem por objetivo, segundo Schlüter (2003, p. 77), realizar uma “descrição sistemática, objetiva e precisa das características” de um determinado objeto de estudo.

As pesquisas de natureza descritiva podem ser conduzidas sob uma abordagem quantitativa, qualitativa ou uma mescla de ambas (DENCKER, 2000). Para este estudo, optou-se pela combinação de métodos quantitativos e qualitativos, uma vez que a operacionalização da pesquisa foi dividida em três fases e cada uma delas apresentou características próprias que demandavam abordagens distintas.

A primeira etapa deste estudo consistiu na realização de uma pesquisa bibliográfica sobre educação turística que identificou diversos artigos, livros e teses sobre o tema, bem como de uma pesquisa documental nas Secretarias de Educação de Recife e Olinda com o intuito de verificar quantas escolas municipais ofertavam o Ensino Fundamental II nestes municípios, tendo sido obtida uma lista contendo nome, endereço e telefone de 42 escolas, sendo 31 localizadas no Recife e 11 em Olinda.

A segunda fase consistiu na realização de um levantamento, do tipo survey (FREITAS et al., 2000), neste universo de escolas, objetivando identificar quantas e quais já tinham utilizado o turismo como prática pedagógica, além de caracterizar essa experiência. Como instrumento de coleta de dados, foi elaborado um questionário contendo 14 perguntas, das quais 9 foram fechadas e 5 abertas. Para agilizar a pesquisa, 
a coleta de dados deu-se por correio eletrônico. Teve-se o cuidado de fazer contato telefônico prévio com os gestores escolares a fim de explicar o intuito da pesquisa e solicitar o email para envio do questionário. Nesse momento, esbarrou-se em dificuldades, como o número de telefone fornecido pelas secretarias inexistente ou onde ninguém atendia; não foi possível falar com alguns gestores; e houve recusa por parte de uma gestora em participar da pesquisa sob a alegação de que não teria tempo. Deste modo, das 31 escolas de Recife, o questionário foi enviado para 24 e, das 11 escolas de Olinda, enviou-se o questionário para 9 delas, totalizando uma população de 33 escolas.

Obteve-se resposta de 21 escolas, sendo 15 localizadas em Recife e 6 em Olinda, correspondendo a uma amostra de metade do universo da pesquisa. Os resultados foram tabulados no software Excel e analisados estatisticamente por meio da técnica de análise de frequência. Foram identificadas 9 escolas que tiveram algum tipo de experiência com o turismo enquanto prática pedagógica.

A terceira e última fase envolveu apenas as 7 escolas, identificadas na etapa anterior, cujos gestores afirmaram trabalhar o turismo como tema transversal ou como disciplina, visando aprofundamento dos dados. Elas compuseram a amostra, de tipo não probabilística e intencional, da pesquisa qualitativa cujo objetivo foi identificar de que maneira foi feita a inclusão do turismo na escola, bem como os benefícios e as dificuldades da inserção desta prática. Neste intuito, foram realizadas entrevistas semiestruturadas com seus diretores ou vice-diretores, previamente marcadas por telefone. A escolha por este tipo de instrumento de coleta de dados se deu pelo fato de que ele permite ao participante da pesquisa expor suas opiniões e interagir com o pesquisador (COHEN; MANION; MORRISON, 2000). Com a devida autorização dos mesmos, as entrevistas foram gravadas e transcritas no software Word para posterior análise. Os dados foram interpretados por meio da análise de conteúdo (BARDIN, 2008, p. 10) e serão apresentados e discutidos na seção a seguir.

\section{ANÁLISE E DISCUSSÃO DOS RESULTADOS}

Da amostra de 21 escolas investigadas, 12 nunca haviam praticado nenhuma das modalidades da educação pelo turismo, enquanto as 9 restantes utilizavam ou já haviam utilizado o turismo como ferramenta pedagógica. 
Quando questionados sobre as razões para a não inclusão do turismo na escola, metade dos gestores das escolas que nunca adotaram o turismo como prática pedagógica alegou não ter orientação dos órgãos governamentais sobre como fazê-lo. No entanto, a maioria demonstrou interesse em incluir a temática na escola, desde que houvesse uma orientação adequada. Parte dos gestores afirmou que a inclusão da temática seria importante, pois possibilitaria que os alunos conhecessem a localidade, havendo, também, um desenvolvimento pessoal do alunado. Além da falta de orientação, para os gestores, foi mencionada a necessidade de se trabalhar outros temas que foram considerados prioritários, tais como doenças sexualmente transmissíveis, saúde e cidadania. Percebe-se, assim, que eles não vislumbravam o turismo como um instrumento para o estudo de tais temas. Também foram citados outros entraves para a inclusão do turismo como prática pedagógica. Entre eles, destacou-se o desinteresse dos docentes, a falta de recursos financeiros e o fato de ser uma escola de ensino fundamental, já que consideravam a prática mais adequada para o ensino médio e para a educação de jovens e adultos (EJA).

Entre as escolas que trabalhavam ou já haviam trabalhado o turismo, esta prática pedagógica foi adotada em várias séries do ensino fundamental, havendo certa predominância de sua inclusão no $9^{\circ}$ ano. A iniciativa de inserir o turismo nas escolas partiu, principalmente, dos docentes. Houve apenas um caso onde a ação foi idealizada por uma Organização Não Governamental (ONG).

No que se refere à forma de inserção do turismo nas escolas, a grande maioria praticava apenas o turismo pedagógico. Nenhuma das escolas possuía disciplina específica de turismo e apenas uma trabalhou o turismo como tema transversal através de um projeto proposto por uma ONG que consistiu na produção de vídeo sobre pontos turísticos da cidade, com o objetivo despertar nos alunos um olhar crítico da realidade.

Verificou-se uma falta de clareza dos gestores das escolas sobre as possíveis modalidades de aplicação da educação pelo turismo - como tema transversal, como disciplina e/ou com o turismo pedagógico - uma vez que, em diferentes fases da pesquisa, os mesmos gestores afirmaram ter utilizado aplicações distintas para uma única atividade. 
Percebeu-se que, na visão dos gestores pesquisados, a atividade turística acontece apenas por causa do deslocamento (aula-passeio). A fala de um dos entrevistados deixa evidente que não há foco na atividade turística:

Eles [os alunos] não veem o turismo como fenômeno social, [...] na verdade é uma atividade extraclasse. [...] Essa nomenclatura turismo eles não utilizam, a gente não foca que é um turismo [...].

Alguns até mesmo confessaram que abriram os olhos à abordagem do turismo enquanto fenômeno sócio-cultural e econômico após esta pesquisa.

Embora não denominem a realização de aulas-passeio como turismo pedagógico, esta prática ocorre em disciplinas como Geografia, Ciências, Língua Portuguesa, Língua Inglesa, Artes e, sobretudo História. Como o estudo foi feito em dois municípios (Recife e Olinda) cuja importância histórica se mescla com a formação do próprio país, entende-se a facilidade desta disciplina em realizar atividades extraclasses, pois ambas cidades possuem testemunhos em forma de construções, museus e espaços públicos que datam dos primórdios da colonização brasileira. Todavia, chamou atenção a menção feita à disciplina de Língua Portuguesa. Seu envolvimento está atrelado à utilização de textos reflexivos sobre os temas que serão vistos nas aulas-passeio e à confecção dos relatórios posteriores, tal como explicado por um dos entrevistados:

[...] trata das questões em textos, textual, a construção do texto, aquilo que foi visto tanto na oralidade, quanto na escrita. Primeiro a gente trabalha o conteúdo. Depois vai pra o campo. Aí voltando do campo eles fazem um relatório ou uma conversação em grupo, porque nem sempre todos os alunos vão, os pais não permitem, aí ou faz uma conversação para que os alunos debatam com aqueles que não acompanharam a equipe, ou então fazem um relatório.

Constatou-se haver o desenvolvimento de um trabalho interdisciplinar que se inicia na escola, com a abordagem do tema que será visto na sala de aula, como declara um dos entrevistados: "Os professores dentro da sua disciplina fazem uma pesquisa sobre determinado local”. Posteriormente, há a aula-passeio para a contextualização do assunto e por fim acontecem as atividades de finalização que podem ser relatórios, redações e debates, considerando que este último é imprescindível para a culminância deste processo, porque além de compartilhar as vivências com os alunos que não 
puderam participar da atividade, há o confronto de pontos de vista e o esclarecimento de possíveis dúvidas. Pode-se, portanto, afirmar que a prática do turismo pedagógico é bem estruturada, na medida em que os professores procuram trabalhar de maneira interdisciplinar buscando cumprir as três etapas fundamentais (que ocorrem antes, durante e depois da atividade) para a maximização dos seus benefícios.

Das 7 escolas cujos gestores foram entrevistados, o envolvimento dos docentes foi considerado bom $(n=4)$ e ótimo $(n=3)$. Já o envolvimento dos alunos foi avaliado como ótimo $(n=6)$ e bom $(n=1)$. Na percepção de um dos gestores, os alunos:

[...] costumam ser bem participativos, assim, se envolvem bastante. Participam (da preparação), porque ficam na ansiedade de ter um bom desempenho pra poder aproveitar o máximo quando chegar o período dessa aula de campo.

Outro aspecto positivo destacado pelos gestores foi a possibilidade de dar aos alunos a chance de "reconhecer a sua cidade e os seus pontos turísticos. Despertar no aluno o sentimento de cidadania e pertencimento em relação a sua cidade". Ressalta-se que devido às condições financeiras do público atendido por estas escolas (que em geral é de baixa-renda), visitas a determinados locais, muitas vezes, somente são oportunizadas pela escola.

A avaliação positiva do turismo pedagógico deve-se ao fato dele ser um importante instrumento para o enriquecimento do processo de ensino-aprendizagem, uma vez que, além de se caracterizar como uma atividade lúdica, possibilita a contextualização dos conteúdos vistos em sala de aula. Como afirma Peccattielo (2005), a interação entre professores, alunos, recursos didáticos, meio social e o resgate da vivência e da percepção cultural que esta atividade possibilita auxiliam os estudantes a construir significados sobre os conteúdos da aprendizagem.

Quando questionados sobre as principais dificuldades encontradas na implantação do turismo na escola, os entrevistados destacaram a escassez de material didático específico. Com exceção das cartilhas oferecidas por programas governamentais, não há livros específicos que abordem como incluir tais atividades no ensino básico e há poucos exemplos que possam servir de referência para a condução destas atividades. Vale salientar que, embora tenha havido três programas federais para a inclusão do turismo na escola (FONSECA FILHO, 2007; 2010; FONSECA FILHO; 
ALDRIGUI, 2009; MTUR, 2007), nenhuma das escolas que compuseram a amostra desta pesquisa participou de alguma destas iniciativas.

Por fim, outra dificuldade apontada pelos gestores foi a falta de recursos financeiros para a contratação de transporte. Como os alunos não tem como arcar com os gastos de deslocamento e o orçamento destinado às escolas tem que suprir outras demandas, os gestores precisam buscar fontes alternativas para viabilizar as excursões didáticas. Lamentando-se da escassez de recursos financeiros, um dos gestores coloca que:

[...] gostaria de poder mais, como eu disse a você, ter mais condições financeiras para poder tentar mais, comprar os materiais que faltam, como a questão pra poder deslocar eles. [...] É uma pena que não tenho recurso para mais, passar mais dias com os alunos, tem que ir e voltar no mesmo dia e com sacrifício.

Os resultados apresentados apontam para a necessidade de capacitação dos gestores e professores das escolas públicas de Recife e Olinda visando potencializar os benefícios que as modalidades da educação pelo turismo podem proporcionar.

\section{CONSIDERAÇÕES FINAIS}

Não obstante as potencialidades de extrair benefícios da educação pelo turismo, como demonstrado no decorrer deste artigo, constatou-se que das 42 escolas públicas municipais que estavam ofertando o Ensino Fundamental II em Recife e Olinda, apenas 9 adotavam alguma modalidade de educação pelo turismo. Por se tratar de destinos turísticos consagrados, nacional e internacionalmente, esperava-se um número mais expressivo, bem como havia expectativa de que o turismo fosse trabalhado também como tema transversal e disciplina, não restringindo-se apenas à prática do turismo pedagógico.

Verificou-se que as possibilidades de inclusão do turismo na escola acabam sendo limitadas em função da falta de conhecimento e de orientação de como poderiam ser adotadas as modalidades da educação pelo turismo, bem como devido à escassez de recursos financeiros para viabilizar tais práticas pedagógicas. 
Acredita-se que, para além da realização do turismo pedagógico nas escolas estudadas, a temática do turismo nos municípios de Recife e Olinda deveria ser trabalhada transversalmente pelas disciplinas que possuem maior afinidade com o tema, ou mesmo, dentro dos temas transversais propostos pelos PCNs (MEC, 1997), proporcionando um diálogo entre estas. Sendo assim, o turismo pedagógico não seria descartado desta proposta. Da mesma forma como acontece atualmente, serviria como atividade complementar às disciplinas tradicionais.

As escolas devem discutir os principais temas e problemas de interesse da sociedade, de modo a oferecer respostas às suas indagações e necessidades. $\mathrm{O}$ vínculo entre assuntos previstos no currículo básico das escolas e as temáticas que envolvem a atividade turística é de grande importância nos municípios de interesse turístico, pois aproxima o aluno da realidade do meio em que ele vive e, com isso, além de contribuir para a assimilação dos temas abordados nas disciplinas tradicionais, desenvolve no educando uma consciência cidadã e crítica em relação ao que acontece ao seu redor.

Para que haja a inclusão do turismo da maneira como é proposta por este estudo, com base na literatura analisada, é necessário que exista uma aprofundamento do tema por parte dos teóricos do turismo e da educação, a fỉm de que a produção científica se diversifique e com isso possa orientar e esclarecer professores e gestores sobre os benefícios de inserir esta temática nas escolas pertencentes a municípios de interesse turístico.

Esperando despertar interesse de outros estudiosos, recomenda-se a realização de pesquisas para complementar e aprofundar as discussões sobre a educação pelo turismo, envolvendo não apenas gestores, como aconteceu neste estudo, mas também docentes e alunos. A academia pode e deve contribuir para a sensibilização de secretários de educação e de turismo, municipais e estaduais, bem como, de toda comunidade escolar, no sentido de desenvolverem projetos conjuntos visando extrair os benefícios da valiosa relação que se pode estabelecer entre turismo e educação.

\section{REFERÊNCIAS}

ANDRADE, J. V. Turismo: fundamentos e dimensões. 8. ed. São Paulo: Ática, 2006. 
ANDRIOLO, A.; FAUSTINO, E. Educação, turismo e cultura: a experiência de estudantes paulistas em Uruçanga. In: RODRIGUES, A. B. (org.). Turismo e desenvolvimento local. São Paulo: Heucitec, 1997. p. 164 -178.

ANSARAH, M. G. R. Formação e capacitação do profissional em turismo e hotelaria: reflexões e cadastro das instituições educacionais do Brasil. São Paulo: Aleph, 2002.

ARAÚJO, U. F. Os temas transversais e os Parâmetros Curriculares Nacionais. In: BUSQUETS, M. D. (Orgs.) Temas transversais em educação: bases para uma formação integral. 4. ed. São Paulo: Ática, 1998. p. 9-17.

BARDIN, L. Análise de Conteúdo, 4. ed. Lisboa: Edições 70, 2008.

BARRETTO, M. Manual de iniciação ao estudo do turismo. 13. ed. Campinas: Papirus, 2003.

BENI, M. C. Análise estrutural do turismo. 5. ed. São Paulo: SENAC, 2001.

BONFIM, M. V. S. Por uma pedagogia diferenciada: uma reflexão acerca do turismo pedagógico como prática educativa. Revista Turismo Visão e Ação, 12 (1), Jan./abr. 2010, p. 114-129. Disponível em: <www.univali.br/revistaturismo> Acesso em: 03/06/2010.

. Lei no 9.384, de 20 de dezembro de 1996. Estabelece as Diretrizes e Bases da Educação Nacional. Diário Oficial da União, Brasília, DF, 23 de nov. 1996.

BRASIL. Estatuto da criança e do adolescente. 7. ed. Brasília: Câmara dos Deputados, Edições Câmara, 2010.

COHEN, L.; MANION, L.; MORRISON, K. Research methods in education. 5. ed. Londres: RoutledgeFalmer, 2000.

DENCKER, A. F. M. Métodos e técnicas de pesquisa em turismo. 4. ed. São Paulo: Futura, 2000.

FONSECA FILHO, A. da S. Educação e Turismo: Um estudo sobre a inserção do turismo no ensino fundamental e médio. 187 p. Dissertação (Mestrado em Didática, Teorias de Ensino e Práticas Escolares) - Faculdade de Educação, Universidade de São Paulo, São Paulo. 2007.

A Educação Turística no Âmbito da Educação Básica: um relato sobre as experiências das escolas estaduais de Ponta Grossa-PR. In: SEMINÁRIO DA ASSOCIAÇÃO BRASILEIRA DE PESQUISA E PÓS-GRADUAÇÃO EM TURISMO, 7, 2010, São Paulo. Anais... São Paulo: Aleph, 2010.

; ALDRIGUI, M. O Turismo como tema transversal na educação básica: o projeto "Caminhos do Futuro". In: SEMINÁRIO DA ASSOCIAÇÃO BRASILEIRA 
DE PESQUISA E PÓS-GRADUAÇÃO EM TURISMO, 6, 2009, São Paulo. Anais... São Paulo: Aleph, 2009.

FREITAS H.; OLIVEIRA, M.; SACCOL, A. Z.; MOSCAROLA, J. O método de pesquisa survey. São Paulo/SP: Revista de Administração da Universidade de São Paulo. São Paulo, v. 35, n. 3, jul./set. 2000, p. 105-112. Disponível em: <www.rausp.br>. Acesso em: 19/11/2010.

MINISTÉRIO DA EDUCAÇÃO E DO DESPORTO. Secretaria de Educação Fundamental. Parâmetros curriculares nacionais: apresentação dos temas transversais e ética. Brasília: MEC, 1997.

MINISTÉRIO DO TURISMO (MTUR). Estruturação e Gestão dos 65 Destinos Indutores. Disponível em:

$<$ http://www.turismo.gov.br/turismo/programas_acoes/regionalizacao_turismo/65destin os.html>. Acesso em: 23/11/2010.

Série Caminhos para o Futuro. São Paulo: IPSIS, 2007. Disponível em: <http://www.turismo.gov.br/turismo/o_ministerio/publicacoes/cadernos_publicacoes/09 caminhos.html >. Acesso em: 23/11/2010.

MOESCH, M. A produção do saber turístico. 2 ed. São Paulo: Contexto, 2002.

NADER, N. G.; POZZI, A.; CONGRO, C. R. Turismo e Educação: a prática do turismo pedagógico no ensino fundamental no Pantanal. In: SIMPÓSIO SOBRE RECURSOS NATURAIS E SÓCIO-ECONÔMICOS DO PANTANAL, 4, 2004, Corumbá. Anais... Corumbá: SIMPAN, 2004. Disponível em:

<http://www.cpap.embrapa.br/agencia/simpan/sumario/resumos/asperctos/pdf/socio/237 SC_Resumo_Simpan_OK.PDF>. Acesso em: 30/08/2010.

PECCATIELlO, A. F. O. Turismo pedagógico como uma estratégia de ensinoaprendizagem sob a óptica dos Parâmetros Curriculares Nacionais $-3^{\circ}$ e $4^{\circ}$ ciclos do ensino fundamental. Revista Global Tourism. São Paulo, v. 1, n. 2, 2005.

PORTUGUEZ, A. P. Consumo e espaço: turismo, lazer e outros temas. São Paulo: Roca, 2001.

RAYKIL, E. B.; RAYKIL, C. Turismo Pedagógico: uma interface diferencial no processo ensino-aprendizagem. Revista Global Tourism. v. 2, n. 2, nov. 2005. Disponível em:

<www.periodicodeturismo.com.br/site/artigo/pdf/Turismo\%Pedagogico.pdf>. Acesso em: 20/09/2010.

REBELO, S. M. Plano Municipal de Educação Turística/PMET: um modelo para os municípios brasileiros de potencial turístico. Revista Turismo Visão e Ação. Balneário Camboriú (SC), v. 1, n. 2, p. 89-106, 1998.

REJOWSKI, M. Turismo e Pesquisa Científica. Campinas: Papirus, 1998. 
RIBAS, M. H. Educação para o turismo: Olhar de Professor. 2002. v. 5, n. 001, p. 920. Disponível em: <http://redalyc.uaemex.mx/html/684/68450102/68450102.html>. Acesso em: 23/09/2010.

RUSCHMANN, D. de M. Turismo e Planejamento Sustentável: a proteção do meio ambiente. 5. ed. Campinas: Papirus, 1999.

SILVA, S. D. C. de M. Turismo e Desenvolvimento em Bezerros - Pernambuco. A expansão da educação turística numa perspectiva de resgate da cidadania. 168 p. Dissertação (Mestrado em Gestão e Políticas Ambientais). Universidade Federal de Pernambuco, Recife. 2002.

SILVA JÚNIOR, E. P. da. Programa de inclusão da disciplina "Estudos Turísticos e Meio Ambiente" nos municípios turísticos do estado do Rio de Janeiro. Caderno Virtual de Turismo. v. 4, n. 2, p. 25-31. 2004.

SILVEIRA, C. R. F. D. da; MARTINS, P. C. S.; VIEIRA, F. S. Turismo Pedagógico em Dourados/MS: uma atividade educacional. In: SEMINÁRIO DE PESQUISA EM TURISMO do MERCOSUL, 5., 2008, Caxias do Sul. Anais... Caxias do Sul, SeminTUR, 2008.

SCHLÜTER, R. Metodologia da Pesquisa em Turismo e Hotelaria. Tradução de Tereza Jardini. São Paulo: Aleph, 2003.

TRIVIÑOS, A. N. S. Introdução à Pesquisa em Ciências Sociais: a pesquisa qualitativa em educação. São Paulo: Atlas, 1987.

UNESCO. Lista do Patrimônio Mundial no Brasil. Disponível em: $<$ http://www.unesco.org/new/pt/brasilia/culture/world-heritage/list-of-world-heritagein-brazil/>. Acesso em: 05/04/2013.

VINHA, M. L.; GARCIA, M. D.; ROMÃO, C.; LUCHESI, D. OLIVEIRA, Y.; MARIN, F.; BOTELHO, F.; GIACOMO, F.; SCACCHETTI, M. C. F. O Turismo Pedagógico e a Possibilidade de Ampliação de Olhares. Revista Hórus - Revista de Humanidades, Ciências Sociais Aplicadas e da Saúde. Ourinhos, nov. 2005. v. 3, n. 3, p. 1-15. Disponível em: <http://www.faeso.edu.br/horus/>. Acesso em: 25/10/2010.

Recebido em: 30-11-2012

Aprovado em: 30-12-2012 